\title{
A comparison of antioxidant activities and tyrosinase inhibitions in fresh white radish, garlic and ginger
}

\author{
Apisit Somman ${ }^{1, *}$, Napa Siwarungson ${ }^{2, *}$ \\ 1 Programs in Biotechnology-Faculty of Science-Chulalongkorn University (CU), Pathumwan, \\ Bangkok 10330, THAILAND \\ ${ }^{2}$ Department of Biochemistry-Faculty of Science - Chulalongkorn University (CU), Pathumwan, \\ Bangkok 10330, THAILAND
}

\section{Keywords:}

2,2-diphenyl-1-picrylhydrazyl

Total Phenolic Content

Flavonoid

Tyrosinase

White radish

Garlic

Ginger

Received: 28 July 2014

Accepted: 27 July 2015

Published: 15 October 2015

\begin{abstract}
Thailand has diverse plant foods, e.g., fruits and vegetables, which contain a Significant amount of biologically active components and biochemical functions that may benefit human health. In particular, they contain the phenolic compound that constitutes natural sources of antioxidants. The current study aims at determining antioxidants, e.g., flavonoids, total phenolic content (TPC), and tyrosinase inhibition, in these fresh vegetables. Data are gathered from three representative markets in Bangkok and further analyzed for discovering any antioxidant activity by observing DPPH radical scavenging, flavonoids, TPC, and tyrosinase inhibition activity. The results show that DPPH radical scavenging activities of white radish, garlic, and ginger are $30.42 \%, 11.39 \%$, and $75.24 \%$ in Pathumwan, Bangrak, and Ratchathewi, respectively. The highest flavonoids of white radish, garlic, and ginger are $2.9 \mathrm{mg} / 100 \mathrm{~g}, 8.38 \mathrm{mg} / 100 \mathrm{~g}$, and $9.81 \mathrm{mg} / 100 \mathrm{~g}$ in these regions, respectively. Meanwhile, the TPC of garlic, ginger, and white radish is $1.94 \mathrm{mg} / 100 \mathrm{~g}, 1.82 \mathrm{mg} / 100 \mathrm{~g}$, and $0.57 \mathrm{mg} / 100 \mathrm{~g}$ in the same places, respectively. Then, the highest tyrosinase inhibition activity of white radish, garlic, and ginger are $137.35 \%$, 114.25\%, 518.72\% in Pathumwan, Ratchathewi, and Ratchathewi, respectively. Therefore, they appear to be a good candidate for intermediary between fresh and salt-processed due to their capabilities to inhibit tyrosinase and oxidation.
\end{abstract}

(C) 2015 The Author(s). Published by TAF Publishing.

\section{INTRODUCTION}

Thailand is a tropical country with a biodiversity of plant foods. There are vegetables and fruits that provide excellent health benefits because they are a

\footnotetext{
*Corresponding author: A. Somman and N. Siwarungson

E-mail: up_to_you_boy@hotmail.com ; siwarungnapa@gmail.com
} 
good source of and tyrosinase inhibition from phytochemicals, e.g. flavonoid, phenolic that are good for preventing diseases. Nowadays, people have an interest consuming healthy foods because these foods promote a healthy life and prevent non-communicable diseases (NCDs), e.g. cardiovascular, heart diseases, diabetes, caused by free radicals, environments, etc. It has been suggested that fruits, vegetables, plants are the primary source of antioxidantduring diet. Natural 16 antioxidants may have free-radical scavengers, reducing agents, complexes of pro oxidant metals, quenchers of singlet oxygen, etc. Free radicals with one or more unpaired electrons (superoxide, hydroxyl, peroxyl) are generally produced in normal or pathological cell metabolism, while compounds that can scavenge them have a great potential in ameliorating diseases and pathological cells. Thus, antioxidants play an important role to protect human body against damages imposed by reactive oxygen species [1]. In general, flavonoid exists within the leaves, flowering tissue and pollens. It is an important part of diet due to their effects on human nutrition. The properties of flavonoid include free-radical scavenging, strong antioxidant activities, the inhibition of hydrolytic and oxidative enzymes, and an anti-inflammatory [2]. Tyrosinase (monophenolmonooxygenase, E:C:1.14. 18.1) with polyphenol oxidase (PPO) is a copper containing enzyme. The enzyme is known as being responsible for enzymatic browning in plants, producing undesirable changes in color, flavor and nutritive values of plant-derived foods and beverages [3]. Tyrosinase has a unique function to catalyze two distinct reactions during melanin synthesis, including the hydroxylation of L-tyrosine to L-dopa and the oxidation of L-dopa to dopaquinone, after further series of conversions to the melanin produced [4]. Tyrosinase inhibitors are chemical agents capable of reducing enzymatic reactions, e.g. kojic acid. Radish (Raphanus sativus), Garlic (Allium sativum) and rhizomes of ginger plant are eatable in raw or cooked as vegetables and used for flavoring food [5].

\section{LITERATURE REVIEW}

In recent years, plant foods (vegetables and fruits) have been studied in terms of the state of antioxidant and anti-tyrosinase within white radish, garlic and ginger local species in various countries (China, Japan, etc.), There is a diversity of the species, while some of them have local names, e.g. Hua Chai Tao, Kratium Thai and Khing, respectively, in Thailand. However, scientists have been attempted to focus only on the characteristics of functional foods that promote healthy and prevent diseases. Kamkaen et al. [6] have observed Chinese radish in Ongkharak district, Nakhonnayok province, Thailand, to discover that Raphanus sativusin contains $50 \%$ propylene glycol, exerting a considerable level of in vitro mushroom tyrosinase inhibition $(78.98 \%$ and $88 \%$, respectively) compared to positive controls of kojic acid within the same solvent systems (65\% inhibition in methanol and $82 \%$ inhibition in 50\% propylene glycol). In Brazil, Queiroz et al. [7] have conducted a research to evaluate the antioxidant activity of fresh garlic, including its commercialized products, and their shelf life. The study discovers that free radical-scavenging activities decrease during the shelf life of all observed products that correlate with a decrease in the total polyphenol content. Besides, Chan et al. [5] have studied total phenolic content (TPC) in the leaves of 26 ginger species. Of the 26 
species, leaves of Etlingera species have the highest TPC. Eleven of these 14 species have a significantly higher TPC in leaves than in rhizomes. Then, Stoilova et al. [8] have conducted a study on ginger extraction in Bulgaria. The total phenols of the alcohol extract being reached are found at $870.1 \mathrm{mg} / \mathrm{g}$ dry extract and DPPH scavenging at $90.1 \%$. Despite having well known for a variety of vegetables, local consumption tables in Thailand contain limited data on antioxidant, anti-tyrosinase, flavonoid and phenolic in local species of white radish, garlic and ginger [9]. This study aims at analyzing these species to investigate antioxidant activity, tyrosinase inhibition, flavonoid and phenolic content per 100 grams at representative markets in Bangkok, Thailand.

\section{RESEARCH METHOD}

\section{Materials}

Local white radish, garlic and ginger are collected from representative markets in Bangkok, Thailand. Besides, 2,2-diphenyl-1-picrylhydrazyl (DPPH), tyrosinase from mushroom, ethanol, sodium nitrite, aluminum chloride, sodium hydroxide, rutin, Folin-Ciocalteu's reagent, sodium carbonate, gallic acid, sodium phosphate, dimethyl sulfoxide (DMSO) are purchased from SigmaAldrich Co. (St. Louis, MO, USA). All the chemicals utilized in the current study are taken at an analytical grade.

\section{Sample Preparation}

A survey on representative markets in Bangkok, Thailand, e.g. Bangrak, Ratchathewi and Pathumwan is conducted over three green groceries at three markets for white radish, garlic and ginger. The extraction method is described by [10]. A sample of 1 gram in $80 \%$ methanol with $10 \mathrm{ml}$ is shaken at $180 \mathrm{rpm}$ speed for 2 hours, while 1,400g is taken into a centrifuge for 20 minutes. The supernatant is filled for analysis. The pellet is re-extracted under identical conditions. The combined supernatants are taken to determine DPPH radical scavenging activity, total flavonoid, total phenolic and tyrosinase inhibition activity.

\section{DPPH Radical Scavenging Activity}

The samples are determined by using a method described by [11]. Each sample $(0.1 \mathrm{ml})$ is mixed with $0.9 \mathrm{ml}$ of $0.5 \mathrm{mM}$ DPPH in ethanol. Then, it is mixed, vortexed and allowed to stand at room temperature for 10 minutes in the dark. The absorbance of the samples is measured at $517 \mathrm{~nm}$ against a blank. Lascorbic acid is taken as positive controls and all tests are conducted in triplicate, while the percent inhibition of DPPH radical scavenging activity is calculated by using the following formula:

$\%$ radical scavenging activities $=[1-($ absorbance of sample $/$ absorbance of control $)] \times 100$

\section{Total Flavonoid}

This step uses a method by Kubola et al. [12]. An extract ( $0.5 \mathrm{ml})$ is mixed with $2.25 \mathrm{ml}$ of distilled water and a $0.15 \mathrm{ml}$ addition of $5 \%$ NaNO2 solution. After 6 minutes, $0.3 \mathrm{ml}$ of $10 \% \mathrm{AlCl} 3.6 \mathrm{H} 20$ solution is added and allowed to stand for 5 minutes before $1 \mathrm{ml}$ of $1 \mathrm{M} \mathrm{NaOH}$ is added and well-mixed. The absorbance is measured at $510 \mathrm{~nm}$. The total flavonoid is discovered as $\mathrm{mg}$ rutin standard curve. 


\section{Total Phenolic}

It is determined by using Folin-Ciocalteu reagent [12]. Briefly, an extract $(0.3$ $\mathrm{ml}$ ) is mixed with $2.25 \mathrm{ml}$ of the reagent and allowed to stand at room temperature for 5 minutes. Then, $2.25 \mathrm{ml}$ of sodium carbonate $(60 \mathrm{~g} / \mathrm{l})$ solution is added to the mixture. After 90 minutes at room temperature, the absorbance is measured at $725 \mathrm{~nm}$. The total phenolic are found as mg gallic acid standard curve.

\section{Tyrosinase Inhibition Activity}

The activity is measured according to Liu et al. [13]. It suggests a preparation of $100 \mathrm{U} / \mathrm{ml}$ tyrosinase in $0.3 \mathrm{ml}$ of $0.1 \mathrm{M}$ sodium phosphate buffer (pH 6.8), in which $0.3 \mathrm{ml}$ samples are mixed by vortexed and incubated at $37 \mathrm{oC}$ for 10 minutes. Then, $15 \% \mathrm{~L}$-DOPA $0.3 \mathrm{ml}$ is added and mixed well, and then incubated at $37 \mathrm{oC}$ for 20 minutes. The $\mathrm{OD}$ value is measured at $475 \mathrm{~nm}$ against a blank, while L-ascorbic acid is taken as positive controls. All tests are conducted in triplicate, and the percent inhibition of tyrosinase activity is calculated by using the following formula:

$\%$ inhibition activity $=[(\mathrm{OD}$ of control - OD of (sample-sample blank $)) / O D$ of control $] \times 100$

\section{Statistical Analysis}

Data are presented as mean \pm standard deviation (SD) of triplicate examinations. A one-sample t-test is taken to do a comparison. A p-value of 0.05 is set to all results as the threshold for being considered as significant.

\section{RESULTS}

\section{DPPH Radical Scavenging Activity}

The DPPH radical assay has been recognized as a suitable model for estimating radical scavenging activities of antioxidants [14]. Table 1 exhibits the percentage of radical scavenging activity (RSA) of white radish, garlic and ginger. The highest RSA of white radish, garlic and ginger are $30.42 \%, 11.39 \%$ and $75.24 \%$ in Pathumwan, Bangrak and Ratchathewi, respectively, in which they are compared to an L-ascorbic acid (vitamin C) concentration $1 \mathrm{mg} / \mathrm{ml}$ as the positive control.

\section{Total Flavonoid}

Flavonoid is a phenolic compound that is widely distributed in plants [15]. In fact, the highest percentage of flavonoid in white radish, garlic and ginger are 2.9, 8.38 and $9.81 \mathrm{mg} / 100 \mathrm{~g}$ in Pathumwan, Bangrak and Ratchathewi, respectively. Table 2 shows the individual flavonoid contents.

\section{Total Phenolic}

Phenolic is widely found in plants, e.g. plant foods, forest plants, etc. [16]. TPC is measured by a spectrophotometry using the Folin-Ciocalteu reagent method [12]. The TPC of white radish, garlic and ginger are found at 0.57, 1.94 and 1.82 $\mathrm{mg} / 100 \mathrm{~g}$ in Ratchathewi, Pathumwan and Bangrak, respectively. Table 3 provides data on the total phenolic contents of each vegetable being observed. 


\section{Tyrosinase Inhibition Activity}

The activity is determined by using a spectrophotometric according to Liu et al. [13]. The highest tyrosinase inhibition activities in white radish, garlic and ginger are $137.35 \%, 144.25 \%, 518.72 \%$ in Pathumwan, Bangrak and Ratchathewi, respectively. Table 4 exhibits the tyrosinase inhibition activity of observed vegetables.

TABLE 1. DPPH radical scavenging activity (RSA) of white radish, garlic and ginger expressed as \%.RSA/100g at 3 markets

\begin{tabular}{lllll}
\hline Markets & White radish & Garlic & ginger & Vitamin C \\
\hline Ratchathewi & $25.60^{\mathrm{A}}$ & $8.81^{\mathrm{A}}$ & $75.24^{\mathrm{A}}$ & $47.65^{\mathrm{A}}$ \\
Prathumwan & $20.37^{\mathrm{B}}$ & $4.49^{\mathrm{B}}$ & $67.46^{\mathrm{B}}$ & $55.36^{\mathrm{B}}$ \\
Bangrak & $30.42^{\mathrm{C}}$ & $11.39^{\mathrm{C}}$ & $70.52^{\mathrm{C}}$ & $57.23^{\mathrm{C}}$ \\
\hline Mean \pm S.D. & $25.46 \pm 5.02$ & $8.23 \pm 3.48$ & $71.07 \pm 3.91$ & $53.41 \pm 5.07$
\end{tabular}

TABLE 2. Total flavonoid of white radish, garlic and ginger expressed as $\mathrm{mg} / 100 \mathrm{~g}$

\begin{tabular}{llll}
\hline Markets & White radish & garlic & Ginger \\
\hline & & & \\
Ratchathewi & 1.70 & 6.56 & 9.81 \\
Prathumwan & 2.90 & 8.38 & 6.24 \\
Bangrak & 1.74 & 5.97 & 7.06 \\
\hline Mean \pm S.D. & $2.11 \pm 0.68$ & $6.97 \pm 1.25$ & $7.70 \pm 1.86$
\end{tabular}

\section{DISCUSSION}

\section{DPPH Radical Scavenging Activity}

The experiments show that the antioxidant activities of white radish, garlic and ginger from three markets have a mean of $25.46 \%, 8.23 \%$ and $71.07 \%$, respectively. In contrast, a comparison with vitamin C concentration $1 \mathrm{mg} / \mathrm{ml}$ as a positive control shows that it has $53.41 \%$ more than white radish but less than ginger. In fact, garlic has the lowest antioxidant activity. Kamkaen et al. [16] have reported that an extract of Chinese radish with propylene glycol exert a considerable level of $50 \%$ antioxidant activity. In this experiment, the solvent is extracted by methanol. White radish and garlic from Bangrak have the best antioxidant activity compared to Ratchathewi and Bangrak, because they are freshly harvested or taken into a good storage. Ginger is the best antioxidant activity in Ratchathewi, Bangrak and Pathumwan, respectively. These experiments indicate that the one-sample test statistical differences show a significant $p$-value $(<0.05)$ between white radish, garlic and ginger at all markets.

The antioxidant may prevent chronic diseases from free radicals by protecting cells, preventing diseases, and promoting a good health. Antioxidants are possible to gather from healthy eating or supplements, e.g. vitamin A, C or E, and anthocyanin, beta-carotene, lycopene, phenolic, etc. In fact, natural and synthetic antioxidant have both been known as reducing cell damages from free radicals and promoting normal functions of cells within human body. 


\section{Total Flavonoid}

Flavonoid is a phenolic in a relationship with phenolic contents. Results indicate that garlic and ginger have the best flavonoid contents due to higher phenolic contents than white radish.

\section{Total Phenolic}

Phenolic compounds are phytochemicals in plants. The findings discover that garlic and ginger have the highest total phenolic contents, more than white radish. Chan et al. [5] have studied the total phenolic content in the leaves of 26 gingers, in which 14 species have significantly higher TPC in their leaves than in rhizomes. Stoilova et al. [8] have conducted a study on the total phenols of alcohol extract reached, which is found at $870.1 \mathrm{mg} / \mathrm{g}$ dry extract. However, the current study focuses on local species from representative markets in Bangkok, which causes differences $[5,8]$.

TABLE 3. Total phenolic contents of white radish, garlic and ginger

\begin{tabular}{llll}
\hline Markets & White radish & Garlic & Ginger \\
\hline Ratchathewi & 0.57 & 1.83 & 1.45 \\
Prathumwan & 0.33 & 1.94 & 1.62 \\
Bangrak & 0.50 & 1.51 & 1.82 \\
\hline Mean士S.D. & $0.46 \pm 0.12$ & $1.76 \pm 0.22$ & $1.63 \pm 0.18$ \\
& & & \\
\hline
\end{tabular}

TABLE 4. Tyrosinase inhibition activity of white radish, garlic and ginger

\begin{tabular}{lllll}
\hline Markets & White radish & Garlic & Ginger & Vitamin C \\
\hline Ratchathewi & $135.16^{\mathrm{A}}$ & $114.25^{\mathrm{A}}$ & $518.72^{\mathrm{A}}$ & $91.04^{\mathrm{A}}$ \\
Prathumwan & $137.35^{\mathrm{A}}$ & $96.80^{\mathrm{B}}$ & $283.70^{\mathrm{B}}$ & $92.45^{\mathrm{A}}$ \\
Bangrak & $116.15^{\mathrm{B}}$ & $111.49^{\mathrm{A}}$ & $439.69^{\mathrm{C}}$ & $98.27^{\mathrm{B}}$ \\
\hline Mean \pm S.D. & $129.55 \pm 11.65$ & $107.51 \pm 9.38$ & $414.03 \pm 119.59$ & $93.92 \pm 3.83$
\end{tabular}

\section{Tyrosinase Inhibition Activity}

The highest tyrosinase inhibition activity is discovered in ginger, followed by garlic and white radish, respectively. Kamkaen et al. [6] have reported in vitro tyrosinase inhibition (78.98\% and $88 \%$, respectively) compared to kojic acid (65\% inhibition in methanol and $82 \%$ inhibition in $50 \%$ propylene glycol), which are different to the current study due to the extraction in methanol. The three markets differ in terms of quality, e.g. fresh, stores in room temperature, humidity, surface moisture, etc. The highest inhibition activity of all samples are significantly higher than the positive control $(p<0.05)$. Then, the tyrosinase inhibition in relationship with antioxidants (phytochemicals in food plants) have been recognized as promoting healthy factors, including antiinflammation, reduce free-radicals, prevent NCDs, etc.

\section{CONCLUSION}

There are a wide variation of phytochemical contents (e.g. flavonoid, phenolic, etc.) in fresh vegetables (white radish, garlic, ginger) commonly consumed in 
Bangkok, Thailand. The consumption is taken based on several measures, including fresh, clean, good practices, good storages, etc. However, many markets are not a good source of fresh vegetables. The data have shown that the issue is currently occurring at three representative markets in Bangkok, Thailand. Moreover, information from this study are useful in selecting raw vegetables for being consumed to promote a healthy life by preventing noncommunicable diseases.

\section{REFERENCES}

1. Govindappa M, Bharath N, Shruthi H, Santoyo G. In vitro antioxidant activity and phytochemical screening of endophytic extracts of Crotalaria pallida. Free Radicals Antioxid. 2011; 1(3): 79-86. DOI: 10.5530/ax.2011.3.11

2. Zhishen J, Mengcheng T, Jianming $\mathrm{W}$. The determination of flavonoid contents in mulberry and their scavenging effects on superoxide radicals. Food Chem. 1999; 64(4): 555-559. DOI: 10.1016/S0308-8146(98)00102-2

3. Karioti A, Protopappa A, Megoulas N, Skaltsa H. Identification of tyrosinase inhibitors from Marrubium velutinum and Marrubium cylleneum. Bioorgan Med Chem. 2007; 15(7): 2708-2714. DOI: 10.1016/j.bmc.2007.01.035

4. Chen C, Kuo P, Chen Y, Huang J, Ho M, Lin R, Chang J-S, Wang H-M. Tyrosinase inhibition, free radical scavenging, antimicroorganism and anticancer proliferation activities of Sapindus mukorossi extracts. J Taiwan Inst Chem E. 2010; 41(2): 129-135. DOI: 10.1016/j.jtice.2009.08.005

5. Chan E, Lim Y, Wong L, Lianto F, Wong S, Lim K, Joe CE, Lim TY. Antioxidant and tyrosinase inhibition properties of leaves and rhizomes of ginger species. Food Chem. 2008; 109(3): 477-483. DOI: 10.1016/j.foodchem.2008.02.016

6. Kamkaen N, Mulsri N, Treesak C. Screening of some tropical vegetables for anti-tyrosinase activity. Thail Pharm Health Sci J. 2007; 2(1): 15-19.

7. Queiroz YS, Ishimoto EY, Bastos DH, Sampaio GR, Torres EA. Garlic (Allium sativum L.) and ready-to-eat garlic products: In vitro antioxidant activity. Food Chem. 2009; 115(1): 371-374. DOI: 10.1016/j.foodchem.2008.11.105

8. Stoilova I, Krastanov A, Stoyanova A, Denev P, Gargova S. Antioxidant activity of a ginger extract (Zingiber officinale). Food Chem. 2007; 102(3): 764-770. DOI: 10.1016/j.foodchem.2006.06.023

9. Charoensiri R, Kongkachuichai R, Suknicom S, Sungpuag P. Beta-carotene, lycopene, and alpha-tocopherol contents of selected Thai fruits. Food Chem. 2009; 113(1): 202-207. DOI: 10.1016/j.foodchem.2008.07.074

10. Kubola J, Siriamornpun S. Phytochemicals and antioxidant activity of different fruit fractions (peel, pulp, aril and seed) of Thai gac (Momordica cochinchinensis Spreng). Food Chem. 2011; 127(3): 1138-1145. D0I: 10.1016/j.foodchem.2011.01.115

11. Jo Y, Seo G, Yuk H, Lee S. Antioxidant and tyrosinase inhibitory activities of methanol extracts from Magnolia denudata and Magnolia denudata var. purpurascens flowers. Food Res Int. 2012; 47(2): 197-200. DOI: 10.1016/j.foodres.2011.05.032

12. Kubola J, Siriamornpun S, Meeso N. Phytochemicals, vitamin C and sugar content of Thai wild fruits. Food Chem. 2011; 126(3): 972-981. DOI: 10.1016/j.foodchem.2010.11.104

13. Liu J, Wu F, Chen L, Zhao L, Zhao Z, Wang M, Lei S. Biological evaluation of coumarin derivatives as mushroom tyrosinase inhibitors. Food Chem. 2012; 135(4): 2872-2878. DOI: 10.1016/j.foodchem.2012.07.055

14. Sanchez-Moreno C. Review: Methods used to evaluate the free radical scavenging activity in foods and biological systems. Food Sci Technol Int . 2002; 8(3): 121-137. DOI: 10.1177/1082013202008003770

15. Anila L, Vijayalakshmi NR. Antioxidant action of flavonoids from Mangifera indica and Emblica officinalis in hypercholesterolemic rats. Food Chem. 2003; 83(4): 569-574. D0I: 10.1016/S0308-8146(03)00155-9

16. Judprasong K, Charoenkiatkul S, Thiyajai P, Sukprasansap M. Nutrients and bioactive compounds of Thai indigenous fruits. Food Chem. 2013; 140(3): 507-512. D0I: 10.1016/j.foodchem.2013.01.057 